\title{
Sidney Harrison Griffith, Sven Grebenstein (eds). Christsein in der islamischen Welt : Festschrift für Martin Tamcke zum 60. Geburtstag
}

Florence Jullien

\author{
(2) OpenEdition \\ Journals \\ Édition électronique \\ URL : http://journals.openedition.org/abstractairanica/45282 \\ DOI : 10.4000/abstractairanica.45282 \\ ISBN : 1961-960X \\ ISSN : 1961-960X \\ Éditeur : \\ CNRS (UMR 7528 Mondes iraniens et indiens), Éditions de l'IFRI
}

\section{Référence électronique}

Florence Jullien, « Sidney Harrison Griffith, Sven Grebenstein (eds). Christsein in der islamischen Welt : Festschrift für Martin Tamcke zum 60. Geburtstag », Abstracta Iranica [En ligne], Volume 37-38-39 | 2018, document 46, mis en ligne le 30 décembre 2018, consulté le 26 septembre 2020. URL : http:// journals.openedition.org/abstractairanica/45282 ; DOI : https://doi.org/10.4000/abstractairanica. 45282

Ce document a été généré automatiquement le 26 septembre 2020.

Tous droits réservés 


\section{Sidney Harrison Griffith, Sven Grebenstein (eds). Christsein in der islamischen Welt : Festschrift für Martin Tamcke zum 60. Geburtstag}

Florence Jullien

\section{RÉFÉRENCE}

Sidney Harrison Griffith, Sven Grebenstein (eds). Christsein in der islamischen Welt: Festschrift für Martin Tamcke zum 60. Geburtstag. Wiesbaden: Harrassowitz Verlag, 2015, x-633 p., ill. ISBN 978-3-447-10441-8.

1 L'ouvrage comporte 36 contributions par des spécialistes du monde chrétien oriental et des relations islamo-chrétiennes au Moyen-Orient. Plusieurs ont trait aux sources syriaques édesséniennes (S. P. Brock, «Perfidious Greeks, Blessed Greeks, Blessed Muslims, and the Memory of Alexander in Dating Formulae of Syriac Manuscripts », p. 13-26; J. Tübach, «Die Personennamen in den Akten der edessenischen Märtyrer Šrbēl und Bar Sāmyā ", p. 27-38), aux échanges intercommunautaires judéo-islamochrétiens (T. Nagel, «Juden, Christen und Muslime: Religionsgeschichtliche Betrachtungen », p. 39-64), aux textes islamiques aussi. Signalons parmi cet ensemble l'article de M. Heimgartner sur la correspondance du patriarche syro-oriental Timothée $\mathrm{I}^{\mathrm{er}}$ comme source pour l'histoire de la paideia chrétienne à Bagdad ( Christian Education in Baghdad: The Letters of the East Syrian Patriarch Timothy I ", p. 173-185); celui de D. G. K. Taylor qui propose une édition du texte syriaque, avec traduction commentée, de la disputatio entre un moine du monastère de Bēth- Halēe et un musulman (" The Disputation between a Muslim and a Monk of Bēt Ḥālē: Syriac Text and annotated English Translation», p. 187-242); la réflexion de G. Reinink sur une légende produite au IX ${ }^{\mathrm{e}}$ siècle dans le milieu de Gundešābuhr sur la reine de Saba («A Syriac Legend of the Qeen of Sheba from 9th-century Gondeshapur », p. 257-268); des 
remarques sur le système éducatif dans l'œuvre de Bar 'Ebrōyō par D. Weltecke («Bemerkungen zum Kapitel über die Schule in Bar 'Ebroyos Huddoye (dem Nomokanon) », p. 299-312) ; ou sur le statut du christianisme au début de l'islam par D. Thomas («The Minimalisation of Christianity under Early Islamic Rule», p. 313-322). Plusieurs contributions viennent documenter l'histoire récente des chrétiens d'Orient.

\section{AUTEURS}

\section{FLORENCE JULLIEN}

CNRS, Mondes iranien et indien, Paris 